\title{
Finding a Way to Tie Technology, Aesthetics and Dramaturgy Together in Terms of Experimental Sound-based Music
}

Leigh Landy / Ilandy@dmu.ac.uk

Music, Technology and Innovation Research Centre, De Montfort University, Leicester, UK

\begin{abstract}
Not many years ago, I gave a keynote at the SPEEC Conference at Oxford University entitled, 'music Technology, Music technology or Music Technology?' (Contemporary Music Review. 32/5: 459-471, 2013) and have continued to investigate the subjects that arose in that talk both as a scholar and as a composer, issues that align strongly with many themes included in this conference's Call for Papers. Suffice to say that some tension was discovered between the two words in that discussion.

This conference's food for thought keynote talk (modified in the form of the current article) focuses on questions including: Where do we stand in terms of art for art's sake in today's world? How has this influenced our understanding of what aesthetics currently signifies? Who are our communities of listeners? And, with this in mind, what roles do or should communication and dramaturgy play in terms of music making? In consequence are the tensions between the words music and technology in any way getting resolved? As fellow keynote speaker, John Richards ${ }^{1}$ and I are currently involved with writing a book dealing with many of these very issues, one of the book's themes, sampling culture, will be used as this article's case study.
\end{abstract}

\section{Keywords}

music technology, sound-based music, music aesthetics, music as a craft, music as a vocation, music as an art, sampling, dramaturgy in music

1 The talk was dedicated to my colleague and fellow keynote speaker, John Richards, as he celebrated his 50th birthday during the conference and therefore was with us, the conference attendees, not his family, on this special day. 
To begin As this text is based on an invited keynote talk, the following words will form a brief launch to the current article. I believe that it is quite important when offering a keynote talk not to just talk about one's own work but instead to attempt to take some of my ideas and thoughts and combine them with the challenge that has been provided by the host. In fact Martin Flašar's conference theme was perhaps easier to write than to respond to given the multiple forms of provocation implied in the questions posed. These provocative thoughts therefore present me with a good challenge. Thus, the following text is in fact my reaction to many of the issues raised in the conference call combined with a personal statement, an attempt to offer those present and future readers food for thought and, perhaps logically, offer a few personal provocative views as part of this reaction. With this in mind the current text is more a statement seeking reaction than a report regarding a specific scholarly research project.

The introduction involves walking through the abstract a little bit as it sets the theme clearly. Not many years ago I presented another keynote at Oxford University that was called 'music Technology, Music technology or Music Technology?' Reading it one notes its nuance, as the first one has a small $\mathrm{m}$ and a capital $\mathrm{T}$, the second one has a capital $\mathrm{M}$ and a small $t$ and the third contains two capitals. The one with two capitals is, in my view, ideal in my field of making music with any sounds given its interdisciplinary nature and tendency towards innovative approaches to both art and technology. However, I actually belong to category number two as I invite technology specialists to offer a helping hand when I need technology developed towards musical goals that I am unable to develop myself. More importantly, I want to state clearly that I definitely do not belong to the first one, which brings us right to the heart of my subject and equally to the challenge posed in the conference call. Why am I proud not to belong to the first one? Because for people who make music that is driven by technology, I would suggest that the percentage of likelihood that a good solid piece of music is going to come out of such an approach is about $1 \%$. Without a founding musical motivation that supports creativity using technology, it is just chance that leads towards a successful work of music. As Martin Flašar's call offered some very interesting, yet challenging thoughts about how technology has almost taken over music, my preliminary contribution is to suggest that technology is ideally a tool supporting musical creativity, not a means leading towards creative goals.

Yet one must be careful about talking about 'good' or 'successful' music, as these terms are relative, open to personal, community or cultural interpretation. We shall return to the word, aesthetics fairly soon. The point here is not so much whether technology has taken over music as such. It is instead whether technology is there to serve musical goals, which it does most of the time. And, of course, there is the often-encountered phenomenon of technology not working properly ...

There is also a third axis here not mentioned in that Oxford title, namely humanities - musicology in the current case - the field which best binds art with technology in terms of various forms of understanding, the field of this conference's community of interest. In the area of sound-based musical creativity, a large percentage of the subject's musicologists consist of artistic practitioners like myself. These are people who are 
able to have both sides of their work inform each other (or all three if they are involved with technological development) using both sides of their brain as it were. They reinforce each other as the intellectual side is helping them to understand their music and their music is helping them to support or question ideas that they are investigating.

Given my own area of expertise and what has been sketched above, the next step is to comment briefly on some of the points raised in the call and then add a few questions of my own that should aid in the article's argument.

\section{Selected subjects from the conference call}

- Music as a craft, music as a vocation, music as art This first point immediately brings us very close to the small and capital $\mathrm{M}$ and $\mathrm{T}$ discussion. A friend once told me that when the arts separated from their original combined state in Western society, the artist (musician-dancer-actor, etc.) became an artisan, that is, a specialist of a given craft. For the purposes of our discussion, I would like to put it slightly differently. My wife, Evelyn Jamieson, is a choreographer who often makes the distinction between someone possessing technique and possessing the ability to perform. Craft is perhaps more aligned with technique and creative imagination and communication more aligned with performance. Possessing technique or craft is undoubtedly important, but in my view, the ability to perform is even more vital. Optimising the two is ideal. Putting it differently, it is about determining one's small and capital c's and p's in craft and performance. As far as vocation is concerned, in my field, there is virtually no one who can earn his or her bread from artistic endeavour alone. Therefore, optimisation is again relevant, such as combining artistic work with the requirements of a position at a university or conservatoire.

- Aesthetic issues of 'high' versus 'low' music As the key discussion regarding aesthetics will be presented in a few paragraphs, I would like to make an important remark at this point regarding 'high' and 'low' music. In Landy 2007, I proposed that what I defined as sound-based music possessed its own paradigm, that is body of knowledge related to creative endeavour, reception and understanding. ${ }^{2}$ Within this paradigm, it was suggested that a good deal of this sound-based repertoire may have roots in forms of art or popular music, but the musician often either ignores or transcends this boundary. This work exists in its own field and is neither dictated by commercial means of production nor by the reasonably declining vector of social relevance that many forms of today's new art music is facing.

- Questions of rationality and irrationality in musical structure and Technologically generated / supported / mediated music As these points are not that pertinent to this discussion, suffice to say that the use of formal approaches to composition, another form

2 Sound-based music was defined as music in which the sound, that is material not normally associated with musical notes, is the unit measure of its content. 
of technological endeavour be it not necessarily involving electricity, works best when founded on a strong musical foundation. This is analogous to the remark above when discussing music Technology. I have often joked (only half seriously): if you can't hear the algorithm, then why use it? There is much more to be said on this subject, but that is best saved for another publication.

- Virtuosity as a product of industrial society This element of the call is a wonderful provocation. However, I would like to 'abuse' its presence by noting that technology is offering a number of new forms of virtuosity today, such as people gaining a high level of mastery of a particular type of studio, of software, of a controller or other new device. Furthermore, virtuosity is being redefined in another way in our time. A six-year-old can become quite virtuosic with the software, Garage Band, due to its rather intuitive approach to music making, just to name one example.

This final point leads to one issue of my own that deserves to be raised

- Issues related to access and inclusivity (on participation and communities) What do I mean by this? In contemporary music, much more than in Janáček's and Bach's time, we have a small public in general. This is no secret to anybody. I have spent over 25 years writing about why this is and whether things have to be this way. I believe that when we are talking about these issues about craft and everything else, if we do not talk about the lack of and, leading from that, the creation of a public, that is, the creation of interest in appreciating and making the music which is very dear to us through establishing a dynamic loop of communication, then we are not doing our work completely. This concentration of the socio-cultural side of our field is a crucial theme, yet one that is hardly investigated. Access is about reaching people. Inclusivity is about making our music open to broader groups of people. Participation is an obvious next step. And community is the heart of the matter, that is, a group of people who share an interest. I would therefore like to offer the following view at this point that many musicians do not think about their potential public, their community, when they make a piece. They make a piece for 'anyone' and hopefully someone will come and listen. I am suggesting here that this is not good enough. In other words, we need to think these things over and include the following questions in our music: why make music in a particular manner and for whom is it intended? Let me put it another way: where does such music fit in today's society? Clearly noise music has, in general, a different audience than does acousmatic music. The latter has roots in high art whilst noise might be said to have roots in popular culture, at least as far as dynamic levels and its venues are concerned. But this is a simplification. Noise music does have a reasonably dynamic community as does today's hacking culture. ${ }^{3}$ Acousmatic music has been presented in a variety of contexts, but when presented as art music, it indeed suffers from a similar lack of community beyond specialists, as does contemporary instrumental music. Does this need to be the case? I believe

3 This is discussed more fully in John Richards' article in this volume. Note: noise music does not need to be loud. So-called 'lower case' music is quiet, often subtle and open to a range of tastes. 
that the answer is a definite 'no' and have been involved with research that provided rich statistics to back up this opinion.

In relation to the above, the following questions will also serve this presentation's argument

- Where do we stand in terms of art for art's sake [uměni pro umění] in today's world? I believe that the two-century old notion of art for art's sake has had an enormous impact on our consideration and definition of aesthetics and I would like to share my view that this impact has been largely negative. We therefore must return to this.

- How do these subjects influence our understanding of what aesthetics currently signifies? This question follows directly from the previous one.

- Who are our communities of listeners? In other words, for whom is our music?

- And, with this in mind, what roles do or should communication and dramaturgy play in terms of music making? We now arrive at the heart of my contribution, be it at the end of a lengthy introduction. These questions are based on an assumption, namely that art, and thus aesthetics, has something to do with communication. Many of the composers who taught me absolutely disagree with that idea. For them, music is a much more intellectual and formal discourse. Nihilistically put, your musical body consists solely of your head. The words, embodiment, emotion and the heart were completely absent in the teaching of composition that I received. I disagreed then and I disagree now. Perhaps I am very conservative in terms of these thoughts. In fact I reject the notion that aesthetics is solely to do with intellectual satisfaction or emotional satisfaction. I believe it is to do with the optimisation of both.

The second term raised here is dramaturgy. When I was taught composition, and to a large extent when I was taught musicology, I learned about what type of artefact a composer (or I) was making and how the piece was made. I learned about the musical grammar of a given work. When studying performance there were equivalents. During those years of study, no one asked me the next two questions that follow from the how and the what of a work. As mentioned above, the third question is why? Why make this piece? This has to do with dramaturgy. It has to do with communication. My contemporaries did not think like this. They made abstract works - nothing wrong there - and were of the view that people could see and hear their abstract compositions and receive them in any way they found fitting. This is a little too simplistic for me actually. I would suggest that there exist particular types of reactions to abstract works. They are not identical to all people but there are these prototypes and there could be dramaturgical concepts supporting communication in such situations. I am not speaking of communication in terms of narrative; there are other means of navigating a work. The second question is for whom - for whom are we making our music? By re-emphasising these questions, I am attempting to underline their importance. Dramaturgy plays a role in terms of the 
issue of 'for whom' as it allows the musician to be able to share intention concepts and receive remarks related to a listener's reception in order to see whether musical communication is actually taking place. It is a means of relating to an audience and learning about developing one's own community, one's own public.

- In consequence, are the tensions between the words music and technology in any way getting resolved? As this talk was presented at a musicology conference I am not going to spend a good deal of time on this question; however, if I were speaking to composers or people studying music technology I could speak for weeks addressing this last question. These people all want to use technology in their music; they want to develop technology for music but the question is: what is the musical advantage of all of this? In other words, the why and for whom are equally relevant here. Expressing the musical advantage or being able to envision the musical advantage of all of this is not always easy but it is possible. That's my profound belief. When technology is developed for its own sake without a clear view of (specific) musical application, we might use the phrase, technology for technology's sake. With this in mind, the expression of the musical advantage regarding the use of a particular technology forms part of dramaturgy and the presence of dramaturgy infers that the small $\mathrm{m}$ and capital $\mathrm{T}$ represent an undesirable combination.

Investigating the sonic musician in the $21^{\text {st }}$ century, in particular sampling culture Fellow keynote speaker, John Richards and I are currently writing a book together, a visionary one, all things going well. We come from two completely different aesthetic worlds but we believe that both are exemplary of many dynamic musical developments in this young century. In his case he specialises in what we call hacking or do-it-yourself culture, He calls his domain that of 'dirty electronics' and that is his focus of study in the book in progress. In my case, the focus is that of sampling culture, something reflecting in a diverse number of musical approaches in my own works for quite some time. Sampling is having a significant impact on our society in a many interesting ways, not solely restricted to music. The same can be said of hacking.

With these two foci in mind, our book, provisionally titled The Music of Sounds and the Music of Things, investigates some important changes in the world of experimental arts practice. One of our discoveries is that there is less importance given in new musical production in recent years to finding new materials, developing new structures, new musical languages or even investigating new approaches to physical space all of which featured in the previous century, particularly in the last forty to fifty years of that century. Instead, our view is that the means of production - in sampling co-production, in DIY culture various means of making - and dissemination are not only becoming more prominent but also changing enormously rapidly in today's experimental music world, which implies the forming of new communities of interest (which are related to new forms of dissemination) and new approaches to dramaturgy. I am aware that musicologists are a little hesitant to look forward because the field's history is based on just that, history, investigating music that already has a trace. However, I believe that these two subjects lend themselves to both 
traditional musicological treatment and investigation of their potential impact on music making, thus a more visionary approach to musicological discourse.

On sampling As stated, my primary role in this book is to investigate sampling. We have known sampling of one form or another in music for quite a number of decades. I suppose that if I asked the reader to come up with an example of early sampling you might think of Pierre Schaeffer's musique concrète in which recordings were made of sounds from the real world and then using them as musical material. If we broaden this history a bit, we might go back to Dada which involved both Marcel Duchamp's found objects, objets trouvés, and the technique of collage employing objects from daily life. We could go back even further, prior to recording technology, and find unexpected objects from the real world included as a musical instrument; however, this article is not intended to survey sampling history. Most of us think of sampling these days with respect to genres such as hip hop music. This is, of course, one of several genres in which samples are employed ranging from the most popular to the most experimental. Although aspects of sampling culture that are also related to hip hop are pertinent, we shall not focus on this genre and similar ones as they are primarily pitch- and note-based music, using sounds that are derived from notes that are intended to be heard as such. Scratching (a percussive sound) and more experimental approaches do take us into the world of timbre and non-note sounds. Our interest is more sound- or timbre-based forms of musical creativity, an area that we believe is increasing in importance within today's musical horizon.

Neither of the book's two approaches, at least in terms of more experimental varieties, lend themselves easily to either high art and low art. Of course there exist works in both areas that possess roots in popular music and most likely involve a regular pulse. However the sonic result will not necessarily suggest that the musicians are popular musicians or were not art music composers. Similarly, there are pieces that have been made by people like myself trained in art/high/serious music, yet these works do not really fit comfortable in either category. Of course some do; the point here is: many do not.

This ability to exist outside of the popular/art divide or, eventually, in an entirely different category of music making, allows us to look at classification in a different way. This is of major importance here because perhaps it suggests an exit from the notion that new music is only for a few people. Furthermore, in the areas of sampling and hacking, but in particular the music of sampling, the material used is familiar to listeners. Therefore, a connection with the material that already exists offers listeners something to hold on to when listening to a work.

Examples that are worthy of mention include the works of John Oswald, the Canadian artist who started the Plunderphonics movement, and his followers. Plunderphonics involves taking very short clips from known music and re-creating it. It is a halfway house between note-based and sound-based approaches that I have called music-based experimental music. It has a common history with hip hop, but it also involves more experimentation and, in Oswald's case, humour. A second and very different type of example is soundscape composition. Here longer recordings are used, from nature, from cities, from anything related to real life and recomposed or, in extreme cases, left as is. 
Soundscape has virtually nothing in common with hip hop. A third area of potential relevance to sampling is that of sound art including the wide diversity of sound installations. Many of these works use samples. Many of these works are also dependent on the context in which they are presented, thus offering another link to community (audience) and to dramaturgy. As sound art works normally do not have a beginning or an end, people can drop in and out as they wish. Installations in public spaces attract a public much larger than the normal contemporary music audience.

In short there is an entire musical world in constant development using samples. The number of people who have had the experience of using samples is absolutely huge, not only in music, but also in writing, in video, in coding, etc. In the world of sampling, although this is not always the case, the notion of co-production, of remix is of relevance. The 'work' is but a form of a work and can be recomposed by the maker(s) and/or by others. How do such works sit with art to art's sake? In another keynote talk, given in 2011, I came up with an antidote, or opposite to art for art's sake, which I called art for life's sake or, alternatively, art for goodness' sake. The idea here is: if we take musical elements from daily life, which you can easily do with sonic material, and organise it imaginatively within an artistic context, you then already have something in common with your listener. If you do something artistic with that material that the listener can actually identify and attempt to follow in time, they indeed have something to hold on to in terms of navigating that work.

Therefore, one might conclude at this point that when one works with sounds one is potentially better able to address communication, dramaturgy and other artistic aspects related to communication than perhaps is the case regarding most more abstract instrumental works. In terms of dramaturgy, communication and aesthetics, it is my view that links with lived experience, e.g., the re-contextualisation of sounds and the art of re-composition, can lead not only to a new, experimental artwork, it can also lead towards a shared experience. ${ }^{4}$ In contrast, traditionally, someone wrote a work and then somebody else stole it, or somebody wrote variations on a piece by someone else. In the world of sampling, something exists, somebody remixes it, somebody re-composes it, etc. The sampled work is a living thing, it is a flexible thing and, following sampling culture, often nobody owns a given piece. In terms of participation, therefore, we have not only composers, we have transformers and we work with co-composers also called sequential composers. Sampling culture opens up creativity allowing people to join together and play with the same sounds and with the same sequences. This is a pronounced anti-highart attitude. In high art: this is my piece, I have the rights, I have the publisher, I have the Supraphon recording and that's it. You can buy the work or you can hear it live or dur-

4 One of the questions raised after the talk concerned the listener's understanding of musical grammars. In my response, I suggested that people who went to performances by Mozart or Beethoven at the time were aware of the grammars prior to their coming and thus could both identify the grammar (shared experience) and the novel approaches within a given piece. This can hardly be said of much contemporary music where structurally many pieces are reasonably unique and the shared experience can be found in the reception of virtuosity and abstraction or perhaps complexity. In sampling culture, the material and, ideally, the treatment of that material, offer experiential links that may not be as strong as that of traditional musical grammars, but at least allow the listener to have something to hold on to in terms of navigating a given work's development in time. 
ing a broadcast or, more recently, online if the rights issues have been dealt with. This is quite different, the opposite in fact, from sampling culture. In terms of communities, inclusivity and the 'for whom factor' tend to be largely built into sampling culture. I find that both interesting and noteworthy. And it goes without saying that there is increased accessibility because a piece possibly has many more people involved with it from its early stages. These musicians do not necessarily call themselves innovative composers in the high art sense; they just enjoy the act of organising sampled sounds. With this in mind, perhaps the notion of composition is becoming redefined, at least for some people in our areas of focus. ${ }^{5}$

Music is not isolated from the other arts as sampling can be applied to just about everything. And certainly sampling in video culture is enormous. There are many stories of videos that have gone viral and have been changed, that is, remixed thousands of times. (See, for example, the history of 'TechnoViking'.) Sampling (remix, mash-up) culture is offering opportunities to many people from all sorts of backgrounds. It is offering new musical challenges and influencing current concepts of musical practice.

Before moving on, there are a couple of aspects related to sampling culture that deserve attention. First of all, there is the question of so-called appropriation. One takes a sample from somewhere. How does that person treat the sample? You can treat a sample of a recording of, say, a politician you do not like in a very negative way, For example, it would be very easy for me to 'grab' a very short recording of Donald Trump and put it into a musical context and make everybody laugh. In this case I am not treating him with respect. I do not want to treat him with respect; I am being clear about this. This could be seen as Brechtian in the sense of political art and satire. However appropriation can become more complex. There are cases in sampling where people hear something exotic such as music from China and use it because it is exotic. However, they are not necessarily treating the sounds with respect, as these sounds perhaps have a particular meaning in China that are not being taken into consideration. What is the musician's attitude in terms of appropriation? This is, I believe, a subject for consideration within both musical and musicological studies if we are going to engage with this field.

The second, crucial aspect that is worthy of attention is to do with legality or illegality and is much more difficult. In fact legality issues associated with sampling, at least currently, might be called its Achilles heel. There are two aspects regarding this subject to be raised. I have composed a series of pieces in which all of the material comes from one nation's radio stations. In many countries this means that the vast majority of the samples that I use are illegally being re-composed in my work. ${ }^{6}$ This being the

5 A second question posed after the talk focused on this notion of redefinition. The reply was indirect as composition is being redefined in a particular way within hacking culture, an area where the expression 'instrument as composition' is often used (that is, that making of a particular instrument serves the subsequent music-making process). More pertinent to the current discussion is the fact that the roles of composer and performer have become fuzzy within many forms of experimental music over the years. In the case of sampling culture, co-composition and ownership represent key subjects related to the dynamic development of the traditional métier of composition.

$6 \quad$ I have been informed that the Czech Radio holds all copyright and can provide samples from their broadcasts for artists to reuse. This is quite exceptional. I am therefore pleased to be making my first legal 
case, why do I go ahead and compose such works? Beyond the satisfaction of seeing a nation's public react to its media being tilted ever so slightly and being presented as an art work, I am taking a small risk to let the world know that current sampling legislation is absurd. To be honest, I believe this largely holds true in hip hop culture as well. You cannot use the sound of a radio station's logo. You cannot use the sound of the advertisements and certainly not much of the music. In the UK the sound of Big Ben is copyright protected. This means it is theoretically impossible to really do anything involving sampling with radio broadcasts. I go ahead and do it because I believe that it is a question of time before the law changes as the law protecting most of these sounds is completely ridiculous.

One of the consequences, bringing me to my second point regarding legality, is the following. A sampling artist within popular music may become quite well known, because the whole thing about popular music is about being popular, being famous and maybe even being rich. In our world of experimental music it is most unusual that a musician wants to become a celebrity, famous or rich. I would even go so far to say that in both sampling and in DIY cultures, we are not looking for more Boulez's and Stockhausen's. We are looking for interesting, exciting musicians. Whether their music outlives them is not that relevant. One French video artist and former collaborator, Michel Jaffrennou, once said to me, l'immortalité est morte, thus immortality is dead. I cannot say whether this is now true or not in both high art or in the new cultures being presented here. Regardless, I believe that it is a question we need to think about, especially with so much art being produced these days with so few opportunities to share it, the Internet being one clear exception. The question is instead: what happens with the sampled works and who are the major figures? I cannot provide you with a lengthy list of names of really interesting sampling artists because many work 'underground' due to the fact that much of their work is illegal. Thus we find ourselves in an awkward situation here - very interesting, perhaps unique in musical history. Again, I believe that these subjects are worthy of further musicological attention in the future. If musicologists can spend months researching how composer $\mathrm{X}$ stole from composer $\mathrm{Y}$, why can they not investigate sample-based works themselves, the thorny issues of sampling and the position of sampled works in today's culture?

[At this point in the keynote, the author presented excerpts from three of his works to demonstrate the breadth of experimentation with sampling. The most traditional involved samples taken from recordings made on the Chinese ocarina, the xūn, played by a master musician. The recordings were re-composed into a sample-based composition, a form of music-based music in the sense of Oswald. The second work utilised texts by Gertrude Stein that were recomposed for live and recorded speaking voices (the same voice as the performer). The third piece was one of the above-mentioned radio works.] Without getting into analysis, two things separate these works from most contemporary art music. 1) If I make a mistake in performing the Stein work even the untrained listener will know. I have often heard performances of Xenakis and Boulez works and been

radio piece in the coming year entitled Mezihlas - Přeshlas - Nahlas or Radio - Voice - Overs in English using recordings from a number of Czech state broadcasters. 
told by the performers that they had made hundreds of mistakes and yet they received enthusiastic applause in the end, as they apparently had been able to communicate the gist of the work. 2) I do not believe that these works need to be destined for contemporary music's micro-public. Given their connection with lived experience, I believe that many people can enjoy any of these experimental works. In fact I have discovered that, without grasping all of the language in the radio piece or the Stein performance or even without the background of Chinese performance traditions regarding the xūn, many people can discover things to hold on to and discover a means of enjoying such works. It then has to do with the level of shared experience (communities), communication and comprehension alongside the level of emotional enjoyment. I therefore again suggest that musicology should open the door to investigating the intention-reception loop of such experimental outings and discover why this music is, in the end, much more accessible than one might imagine, that is, accessible to people in general and to new communities that evolve from their common interest regarding the sampled material and means of production.

To conclude In tackling the challenges presented in the conference call regarding the roles of technology in today's musical cultures and combining these with the areas related to aesthetics found in the title and the sampling culture case study, I have attempted to demonstrate that:

- Innovative music including sound-based music is a subject of study that is of potential importance to musicians and musicologists alike. It is also open to a larger public, group of communities, than most might imagine. As new means of dissemination evolve, these communities will evolve, intersect and evolve further.

- After a period when I was a student and a young composer when everything had to be different than anything that came before it, a period in which neo-atonal music avoided consonance, most new works contained an inaudible structure and John Cage introduced the music of no rules, thus a period of antithesis, a period of synthesis inevitably was to follow. Sampling culture, due to its interest in recycling sounds, is a form of music that allows for both innovative and experiential connections, taking music beyond antithesis.

- With this in mind, aesthetics becomes a notion of optimising intellectual understanding with forms of visceral communication. In general both are based upon relating the musical act of listening to previous experience, also known as knowledge. Communication is therefore integrated into the aesthetic experience. Communities of interest will possess a shared knowledge allowing for this communication to take place. All of this serves experimental music that, often in the past, has avoided this type of discourse.

- In terms of the conference theme, the key contribution here is for technology to serve musical goals. The proposal is, in the end, that those involved with technology work 
closely with musicians (often the same person) and, ideally, with musicologists to holistically demonstrate the musical relevance of a technological or a music-technological development. Aesthetics and dramaturgy can be of invaluable help in terms of supporting this point. This three-way form of communication - between musicians, technologists and musicologists - is valuable for the betterment of technology serving music and for (innovative forms of) music itself.

\section{Bibliography}

LANDY, Leigh. Understanding the Art of Sound Organization. Cambridge, Mass.: MIT Press, 2007. 